\title{
SOSIALISASI DAN EDUKASI PROTOKOL KESEHATAN UNTUK TETAP SEHAT DAN BUGAR BAGI TUKANG SAMPAH DI TEMPAT PEMBUANGAN SAMPAH PENGGILINGAN JAKARTA TIMUR
}

\author{
Sita Dewi $^{1}$, Dwi Listyowati ${ }^{2}$, Bertha Elvy Napitupulu ${ }^{3}$, Francisca Hermawan ${ }^{4}$ \\ ${ }^{1,2,3}$ Sekolah Tinggi Ilmu Ekonomi Jayakarta, ${ }^{4}$ FEB UNIKA Atma Jaya Jakarta \\ *Korespondensi : sitadewi.27@gmail.com, dwilistyowati6@gmail.com, \\ bertha.napitupulu27@gmail.com, francisca.h@atmajaya.ac.id
}

\begin{abstract}
ABSTRAK
Tukang sampah adalah orang yang mengurusi sampah di suatu lingkungan. Tugas mereka adalah membersihkan lingkungan dari sampah dengan cara mengumpulkan kemudian mengangkut sampah tersebut ke tempat pembuangan sampah yang besar, sebelum diangkut lagi ke tempat pembuangan sampah akhir. Di tempat pembuangan sampah besar, sampah-sampah hasil pengumpulan dan angkutan dari lingkungan dipilah lagi, sehingga ada yang masih dapat digunakan lagi, didaur ulang atau benar-benar harus dibuang. Pekerjaan mereka adalah pekerjaan berat, yang memerlukan tenaga dan kesehatan yang baik. Untuk itu mereka harus dapat menjaga kesehatannya sehingga mereka tetap dapat bekerja membersihkan lingkungan. Di daerah Penggilingan Jakarta Timur terdapat tempat sampah besar yang digunakan untuk menampung sampah-sampah dari lingkungan kecamatan Penggilingan, sebelum nantinya sampah akan diangkut ke tempat pembuangan akhir.
\end{abstract}

Kata kunci : sampah, tukang sampah, sehat

\begin{abstract}
Garbage man is the people who work with garbage at any area. They collect, they carry the garbages or rubbishs from every home or building to the big rubbish area that we called dumpster. From the dumpster, all of the rubbish are deliver to another rubbish area that we called the landfill site. At the dumpster, the rubbish is separated to usefull rubbish, to recyle rubbish or useless rubbish. The garbage man have heavy duty. They use their strongness for work and they must be healthy for doing their work. For that reason, garbage man must keep their healty and fit so they can still productive to do keep the area clean.. Penggilingan is an area in East Jakarta, have dumpter to dump any rubbish from any area around Penggilingan, before the rubbish deliver to landfill site.
\end{abstract}

Key word : rubbish, garbage man, health

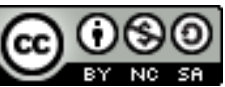

This work is licensed under a Creative Commons Attribution-NonCommercial-ShareAlike 4.0 International License. 


\section{PENDAHULUAN}

Arti sampah menurut Kamus Besar Bahasa Indonesia (KBBI) adalah barang atau benda yang dibuang karena tidak terpakai lagi dan sebagainya; kotoran seperti daun; kertas [1]. Sedangkan menurut Undang-undang Republik Indonesia (UU) no. 18 tahun 2008 sampah adalah sisa kegiatan sehari-hari manusia atau prosses alam yang berbentuk padat [2].

Ada berbagai jenis sampah, yaitu berdasarkan sifatnya, berdasarkan bentuknya, berdasarkan sumbernya. Berdasarkan sifatnya sampah dibedakan menjadi sampah padat (anorganik) seperti plastic, logam, kaca dan sebagainya, kemudian ada sampah basah (organic) seperti sayur, sisa makanan, daun dan sebagainya, serta sampah beracun (B3) seperti batere. Jenis sampah berdasarkan bentuknya sampah dibedakan menjadi sampah padat dan sampah cair, walaupun berdasarkan UU no 18 tahun 2018 sampah hanya berbentuk padat. Jenis sampah berdasarkan sumbernya ada yang merupakan sampah industri yang biasa disebut limbah, sampah konsumsi yaitu sampah yang dihasilkan oleh manusia dari proses penggunaan barang, sampah manusia yaitu sampah hasil pencernaan manusia, sampah alam yaitu sampah yang diproduksi di kehidupan liar melalui daur ulang alami, ada juga sampah nuklir yang merupakan sampah yang dihasilkan dari fusi dan fisi nuklir.

Kita sering mendengar istilah sampah rumah tangga. Berdasarkan UU no 18 tahun 2008 sampah rumah tangga tidak hanya berasal dari suatu keluarga, tetapi juga dapat berasal dari kawasan industri, kawasan komersial, fasilitas sosial dan sebagainya [2]. Maka jenis sampah yang berdasarkan sumbernya dapat digolongkan menjadi 2 golongan utama yaitu sampah rumah tangga yang meliputi sampah dari rumah (keluarga), industri (termasuk perkantoran), sampah konsumsi, sampah nuklir; dan sampah non rumah tangga yang meliputi sampah alam, sampah manusia.

Sampah rumah tangga, biasanya akan dibuang ke tempat pembuangan sampah yang ada di masing-masing rumah tangga. Ada juga yang dibuang secara sembarangan, seperti dibuang di sungai. Setelah dibuang ke tempat pembuangan sampah di masing-masing rumah tangga, sampah akan dikumpulkan dan dibuang ke tempat pembuangan sampah yang lebih besar yang biasa disebut tempat pembuangan sampah sementara (TPS). Di lokasi ini biasanya sampah dipilah dan menjadi sampah-sampah yang dapat didaur ulang (dapat digunakan kembali) dan sampah-sampah yang tidak dapat didaur ulang lagi. Sampah yang tidak dapat didaur ulang akan dibawa ke tempat pembuangan akhir (TPA).

Proses pembuangan sampah dari masing-masing rumah tangga ke TPS, dilakukan oleh tukang sampah. Tukang sampah bekerja cukup berat. Biasanya petugas sampah atau tukang sampah hanya ada beberapa orang untuk suatu kawasan yang cukup luas. Mereka bekerja mengumpulkan sampah rumah tangga dengan menggunakan gerobak. Gerobak yang mereka gunakan ada yang tanpa mesin (harus ditarik oleh mereka sendiri) ada yang bermesin (modifikasi motor yang belakangnya diubah menjadi tempat yang menyerupai gerobak).

This work is licensed under a Creative Commons Attribution-NonCommercial-ShareAlike 4.0 International License. 
Sampah rumah tangga jumlahnya cukup banyak. Petugas yang sedikit menangani suatu kawasan yang cukup luas dengan membawa sampah yang banyak, tentulah suatu pekerjaan berat yang memerlukan tenaga yang besar. Tenaga besar dapat diperoleh bila seseorang dalam kondisi sehat, bugar dan tidak kekurangan makan. Belum lagi kalau cuaca tidak bersahabat, misalnya hujan, tugas tukang sampah akan semakin berat. Berhujan-hujan, mengumpulkan sampah dalam jumlah banyak.

Tukang sampah berjasa dalam membersihkan lingkungan rumah tangga yang ada. Sementara tukang sampah itu sendiri harus bergelut dengan sampah yang identik dengan sesuatu yang kotor. Dengan keadaan seperti ini tukang sampah harus tetap sehat dan juga harus menjaga kebersihan supaya terhidar dari sakit yang berarti aktifitas mengangkut sampah aka terhambat.

Sehat adalah keadaan sehat secara fisik, mental, spiritual maupun sosial yang memungkinkan setiap orang untuk hidup produktif secara sosial dan ekonomis [3]. Menurut Kamus Besar Bahasa Indonesia, sehat adalah kondisi seluruh badan serta bagian-bagiannya terbebas dari sakit [1]. Sedangkan bugar adalah kemampuan tubuh untuk melakukan kegiatan sehari-hari dengan penuh energy dan setelah menyelesaikan kegiatan tersebut masih mempunyai semangat dan tenaga cadangan untuk menikmati waktu senggang dan siap untuk melakukan kegiatan lain yang mendadak/tidak terduga [4]. Cara untuk kita tetap sehat dan bugar diantaranya adalah menjaga makanan dan hidup bersih. Menjaga makanan berarti kita mengkonsumsi makanan yang baik dan bergizi yaitu pola 4 sehat 5 sempurna. Sedangkan hidup bersih berarti kita menjaga kebersihan diri kita sendiri dan lingkungan, misalnya mandi 2 kali sehari, mencuci tangan setelah kita memegang benda yang kita tidak tahu kondisi kebersihannya, mencuci tangan sebelum makan dan sebagainya.

Berdasarkan latar belakang ini, maka kami mengadakan pengabdian masyarakat ke TPS Penggilingan, Jakarta Timur. Di TPS ini terdapat tukang sampah yang melayani pengangkutan sampah rumah tangga di area seluas $449 \mathrm{~km}^{2}$ yang terdiri dari $216 \mathrm{RT} / 18 \mathrm{RW}$. Masalah yang dihadapi tukang sampah di TPS ini seperti yang tergambar di latar belakang, yaitu bekerja berat dan bergelut dengan kotoran. Kami merasa perlu memberikan sosialisasi dan edukasi protokol kesehatan agar mereka tetap sehat dan bugar, sehingga dapat menjalankan tugasnya dengan baik (produktif).

\section{METODE}

Metode untuk melakukan pengabdian masyarakat ini adalah dengan memberikan ceramah secara langsung mengenai kesehatan umum, yaitu menjaga kebersihan, menjaga kesehatan dan kebugaran agar mereka dapat menjalankan tugasnya dengan baik. Kami menekankan ceramah ini ke sumber daya manusianya, yaitu para tukang sampah agar dapat bekerja dengan baik atau mereka produktif dibidangnya.

Adapun tahapan pengabdian masyarakat ini adalah :

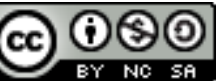

This work is licensed under a Creative Commons Attribution-NonCommercial-ShareAlike 4.0 International License. 
1. Persiapan, yaitu mencari mitra yang menjadi sasaran edukasi dan sosialisasi ini. Selain itu kami juga mempersiapkan dana dan materi pengabdian masyarakat yaitu masalah kebersihan, keshatan dan kebugaran.

2. Survey lapangan, yaitu melihat kondisi tempat pengabdian masyarakat sehingga kami dapat menentukan dengan tepat hal-hal apa yang harus dilakukan pada saat pengabdian masyarakat nanti

3. Pelaksanaan, yaitu waktu melaksanakan pengabdian masyarakat memberi sosialisasi dan edukasi masalah kebersihan, kesehatan dan kebugaran, sehingga tukang sampah menjadi produktif dibidangnya

4. Pelaporan, yaitu membuat laporan pertanggungjawaban atas kegiatan pengabdian masyarakat ini, baik laporan secara intern ataupun laporan luaran berupa penulisan di jurnal.

\section{HASIL DAN PEMBAHASAN}

Sebelum melakukan pengabdian pada masyarakat, kami membuat beberapa persiapan, yaitu mencari mitra, mempersiapkan dana dan mempersiapkan materi pengabdian pada masyarakat.

Mitra kami adalah tukang sampah di TPS Penggilingan Jakarta Timur. Di sini ada kelompko tukang sampah yang dikoordinir oleh Bapak Surono. Kelompok tukang sampah ini bukan kelompok resmi yang dibentuk oleh kelurahan, tetapi mereka memang berkelompok, hitup dan bertempat tinggal di sekitar lokasi TPS. Para tukang sampah ini menganggap bapak Surono sebagai ketua mereka. Selain mencari mitra, persiapan lainnya adalah dana, materi pengabdian masyarakat yaitu mengenai sosialisasi dan edukasi protocol kesehatan untuk tetap sehat dan bugar sehingga tukang sampah ini produktif di bidangnya. Materi sosialisasi dan edukasi diperoleh dari berbagai cara, bekal ilmu yang sudah ada dan ditambah bacaan dan browsing dari berbagai literature online. Dana sebagian diperoleh dari Yayasan Darma Pendidikan yang menaungi STIE Jayakarta, dan sebagian dana mandiri.

Kami mengadakan survey ke lapangan sebelum acara pengabdian masyarakat ini. Survey yang dilakukan pada tanggal 6 Februari 2021.. Survei dilakukan untuk mengetahui kondisi lapangan, atau kondisi lokasi pengabdian pada masyarakat dan jumlah obyek sasaran (tukang sampah). Mengetahui kondisi lokasi diperlukan supaya acara pengabdian pada masyarakat terlaksana dengan baik dan tepat sasaran. Lokasi TPS Penggilingan adalah di Jalan Kali Buaran Rt 006/ Rw 010, Kelurahan Penggilingan, Kecamatan Cakung, Jakarta Timur 13930. Di lokasi ini terdapat 1 bak sampah besar untuk menampung segala jenis sampah rumah tangga yang telah dikumpulkan oleh para tukang sampah dari area sekitar. Tukang sampah membawa gerobak berisi sampah, dan sampah dibuang (dikumpulkan) di bak sampah besar ini. Pembuangan sampah ke TPS ini dilakukan setiap hari.

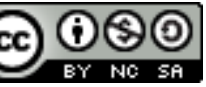

This work is licensed under a Creative Commons Attribution-NonCommercial-ShareAlike 4.0 International License. 
Tukang sampah yang membuang sampah ke TPS ini cukup banyak. Semula perkiraan kami jumlah tukang sampah hanya 50 orang, ternyata jumlah tukang sampahnya ada 175 orang. Tukang sampah ini terbagi dua, yaitu mereka yang mengumpulkan sampah dari berbagai lokasi di sekitar area TPS, misalnya dari komplek perumahan di sekitar, yaitu mereka yang datang dan pergi dengan menarik gerobak sampah, dan ada juga tukang sampah di TPS. Tukang sampah di TPS adalah mereka yang memilah sampah-sampah yang datang. Sampah dipilah menjadi sampah yang masih dapat bernilai uang (di daur ulang misalnya) dan sampah yang sudah tidak bernilai uang, yang langsung dikumpulkan di bak sampah besar yang nantinya akan dibawa ke TPA (tempat pembuangan akhir). Di tempat ini juga terdapat pemukiman non permanen (illegal) yang dihuni para tukang sampah, yang juga tidak jelas apakah mereka mempunyai KTP DKI Jakarta atau bahkan tidak mempunyai KTP. Informasi dari koordinator karena kondisi ini mereka para tukang sampah tidak pernah mendapat bantuan sosial dari pemerintah, baik itu pemerintah pusat ataupun pemerintah DKI Jakarta.

Lokasi TPS Penggilingan berada di jalan yang tidak terlalu lebar, kumuh, bau dan kotor. Sampah yang menggunung karena tidak segera diangkut ke TPA menyebarkan bau dan menimbulkan aliran lendir dari sampah yang ditumpuk. Maka jalan di depan bak sampah besar menjadi becek dan berwarna hitam mengindikasikan kotor. Tukang sampah setiap hari bekerja di lokasi ini, yang berarti bergelut dengan kotoran (sampah yang mereka tangani) dan berada di lingkungan yang kotor. Banyak dari mereka tidak menggunakan penutup hidung (masker) untuk mengurangi bau ataupun untuk mematuhi penerapan 3M di saat pandemic covid-19,yang salah satunya memakai masker. Yang melakukan pemilahan sampah di rumah-rumah di lokasi ini juga masih berkerumun tanpa masker.

Dari hasil survey ini tim pengabdian pada masyarakat merubah strategi. Di awal direncanakan akan dibagikan makan siang ke 50 pekerja sampah di lokasi dan juga membagi masker, sabun serta memberi edukasi dan sosialisasi prorokol kesehatan. Disesuaikan dengan anggaran yang ada, pembagian makan siang dibatalkan tetapi diganti dengan pembagian mie instan dan susu serta sabun. Kami menganggap mie instan dapat dikonsumsi untuk beberapa hari, mengingat mereka tidak pernah mendapat bantuan sosial dari pemerintah. Susu kami bagikan supaya mereka bugar dan tetap kuat bekerja untuk mengangkut sampah. Sabun juga kita bagikan supaya mereka tetap dapat menjaga kebersihan, karena pekerjaan dan lingkungan mereka kotor.

Pelaksanaan Pengabdian pada masyarakat di TPS Penggilingan Jakarta Timur dilaksanakan pada tanggal 10 Maret 2021 jam 10.00 sampai dengan selesai. Tim pengabdian masyarakat memberi bantuan berupa mie instan sebanyak 80 kardus/kotak dimana setiap kotaknya berisi 40 bungkus, 2 kotak sabun lifeboy dimana 1 kotaknya berisi 144 batang sabun dan juga memberi 6 kotak susu cair indomilk siap minum dimana 1 kotaknya berisi 24 botol.

Kondisi jalan yang sempit, adanya bongkar sampah di bak sampah, banyaknya tukang sampah dan gerobak yang terparkir dan orang-orang yang lalu lalang di lokasi, menyebabkan tim pengabdian pada masyarakat kesulitan untuk menyerahkan bantuan. Akhirnya bantuan

This work is licensed under a Creative Commons Attribution-NonCommercial-ShareAlike 4.0 International License. 
diturunkan dengan segera di depan salah satu rumah non permanen tempat tinggal. Tim pengabdian masyarakat tidak dapat berlama-lama menurunkan barang di situ karena sangat mengganggu kelancaran lalu lintas di jalan tersebut.

Untuk acara sosialisasi dan edukasi protocol kesehatan untuk tetap sehat dan bugar dilakukan di tempat lain, yaitu di lahan kosong tidak jauh dari TPS. Di tempat ini tim abdimas melakukan ceramah sinkat kepada para tukang sampah ini untuk tetap sehat dan bugar sehingga mereka dapat terus bekerja mengangkut sampah dari pemukiman ke TPS Penggilingan ini. Ini berarti para tukang sampah diharapkan dapat produktif dalam menjalankan pekerjaannya. Selain itu tim pengabdian masyarakat juga mengingatkan tentang protocol kesehatan, yaitu $3 \mathrm{M}$ yang merupakan memakai masker, mencuci tangan dengan sabun dan air mengalir serta menjaga jarak (tidak berkerumun). Masalah protocol kesehatan $3 \mathrm{M}$ ini tidak nampak dilaksanakan di lokasi TPS Penggilingan ini. Sebetulnya edukasi dan sosialisasi "Protokol Kesehatan untuk Tetap Sehat dan Bugar" kurang direspon oleh mereka (tukang sampah). Selain kami sangat membatasi waktu, karena telah terjadi kerumunan dan kemacetan, tidak ada juga sarana/prasarana untuk pemaparan ceramah kami. Yang juga menjadi kendala juga pada acara ini adalah mereka para tukang sampah ini lebih tertarik pada barang-barang bantuan yang kami berikan. Mereka tidak sabar untuk segera mendapat bagian dari bantuan tersebut.

Secara simbolis, bantuan yang kami berikan diterima oleh koordinator tukang sampah yaitu Bapak Surono. Kepada Bapak Surono, kami berpesan untuk membagi secara merata bantuan yang kami berikan. Proses serah terima secara simbolis ini, kami lakukan di lokasi ceramah. .

Walaupun acara pengabdian pada masyarakat di TPS Penggilingan berjalan singkat, kami berharap bantuan dan edukasi serta sosialisasi yang kami berikan dapat bermanfaat bagi mereka. Berikut ini beberapa foto pengabdian pada masyarakat di TPS Penggilingan. 
TRIDHARMADIMAS: Jurnal Pengabdian Kepada Masyarakat Jayakarta http://journal.stmikjayakarta.ac.id/index.php/tridharmadimas

EmaiL: info@stmik.jayakarta.ac.id , tridharmadimas.jayakarta@gmail.com DOI : 10.52362/tridharmadimas.v1i2.665/halaman : 130-138

E-ISSN: 2798-8295 (Online), P-ISSN: 2798-8554 (Print) Vol. 1, No.2, Desember 2021

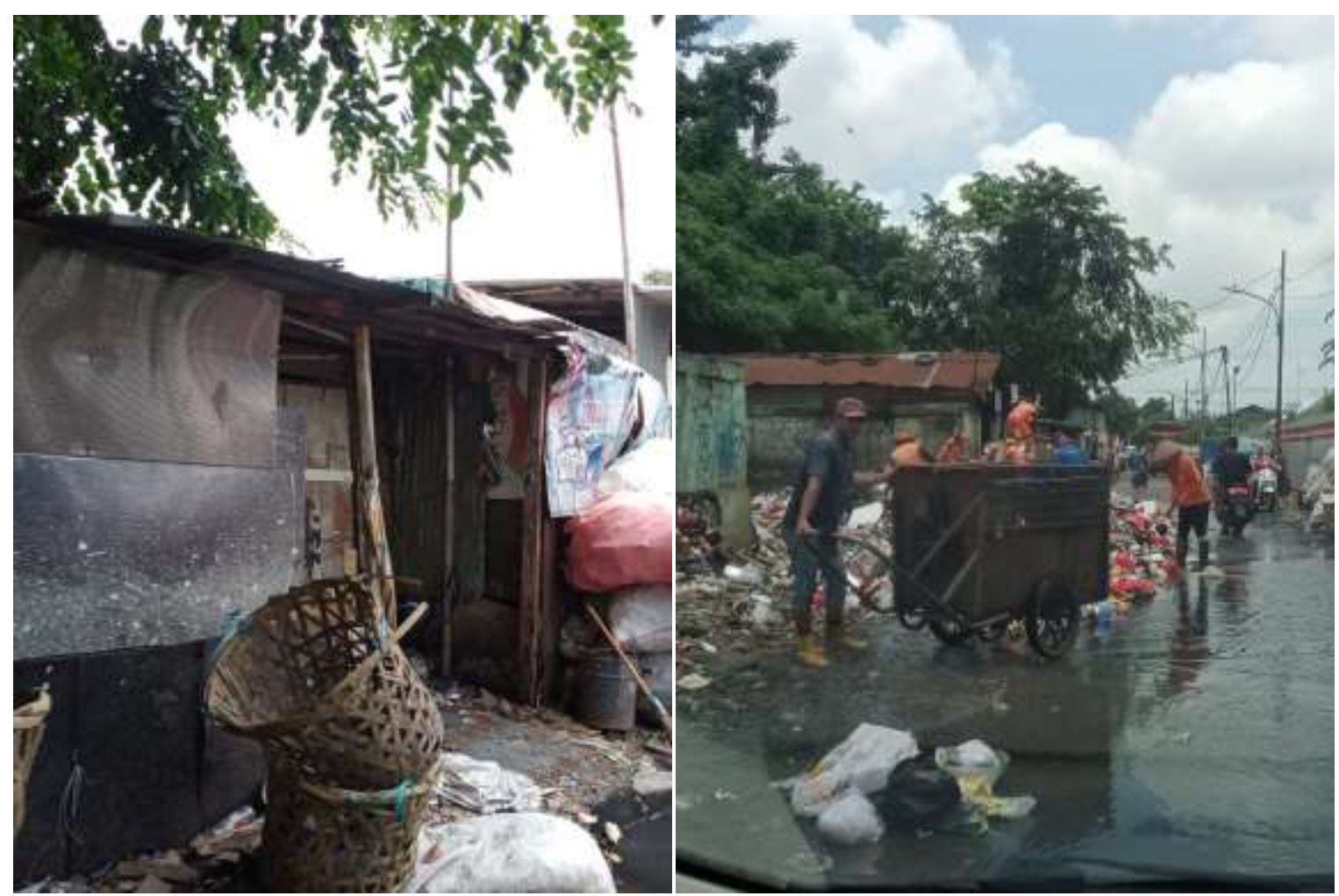

Gambaran lokasi Pengabdian Masyarakat di TPS Penggilinan

Kiri : rumah non permanen

Kanan : Aktifitas bongkar sampah di bak sampah besar

This work is licensed under a Creative Commons Attribution-NonCommercial-ShareAlike 4.0 International License. 
TRIDHARMADIMAS: Jurnal Pengabdian Kepada Masyarakat Jayakarta http://journal.stmikjayakarta.ac.id/index.php/tridharmadimas EmaiL: info@stmik.jayakarta.ac.id , tridharmadimas.jayakarta@gmail.com DOI : 10.52362/tridharmadimas.v1i2.665/halaman : 130-138 E-ISSN: 2798-8295 (Online), P-ISSN: 2798-8554 (Print) Vol. 1, No.2, Desember 2021

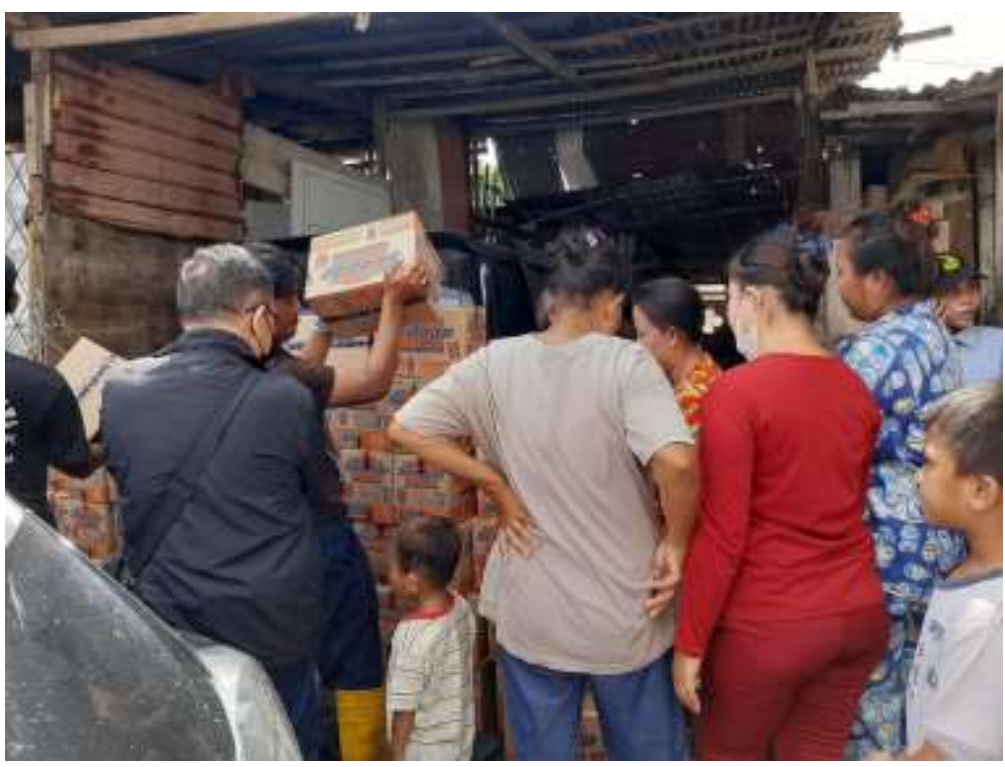

Penurunan bantuan di lokasi, di depan salah satu rumah non permanen

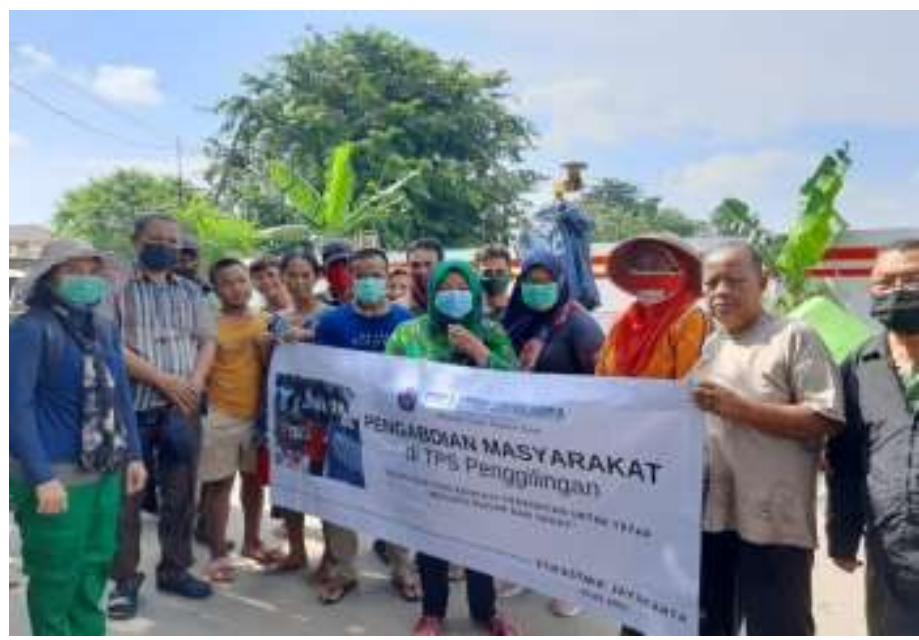

Sebagian tukang sampah yang mengikuti sosialisasi dan edukasi protocol kesehatan untuk tetap sehat dan bugar

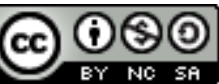

This work is licensed under a Creative Commons Attribution-NonCommercial-ShareAlike 4.0 International License. 
TRIDHARMADIMAS: Jurnal Pengabdian Kepada Masyarakat Jayakarta

http://journal.stmikjayakarta.ac.id/index.php/tridharmadimas

EmaiL: info@stmik.jayakarta.ac.id , tridharmadimas.jayakarta@gmail.com

DOI : 10.52362/tridharmadimas.v1i2.665 /halaman : 130-138

E-ISSN: 2798-8295 (Online), P-ISSN: 2798-8554 (Print) Vol. 1, No.2, Desember 2021

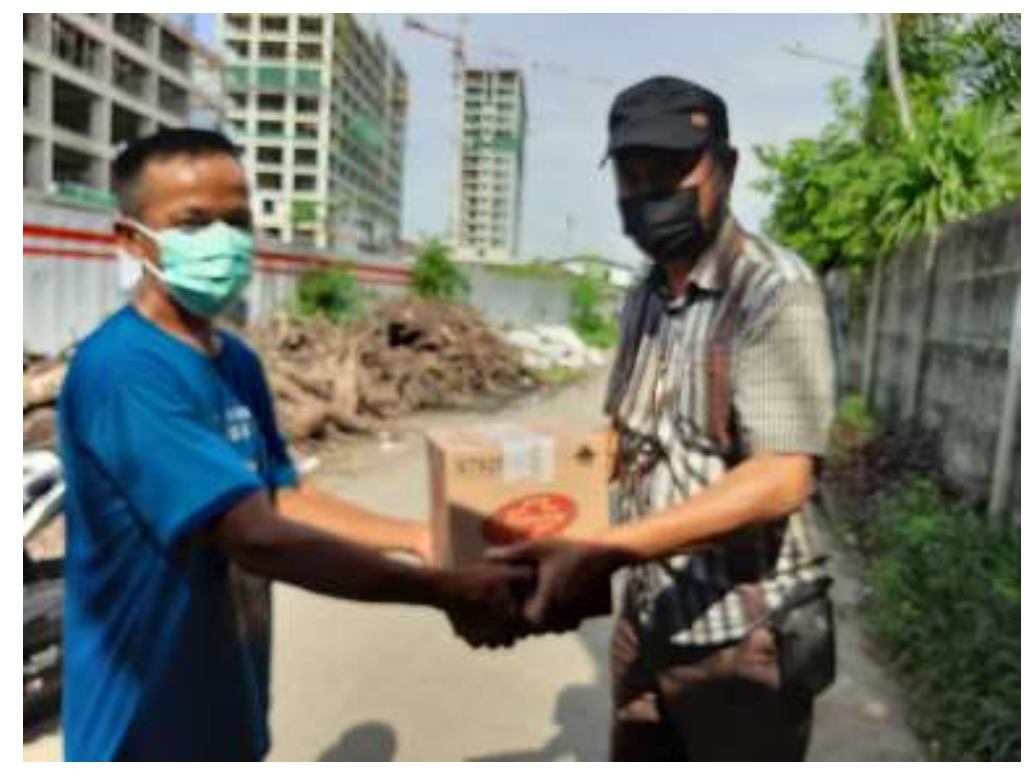

Serah terima bantuan secara simbolis kepada koordinator Bp Surono (kiri) dari tim Pengabdian Masyarakat diwakili oleh Bp Johan (kanan)

\section{KESIMPULAN}

Kegiatan pengabdian masyarakat ini direspon dengan baik ke mitra sasaran, yaitu tukang sampah, terutama bantuan berupa mie instan, sabun dan susu yang diserahkan kepada mereka. Masalah sosialisasi dan edukasi protocol kesehatan untuk tetap bugar dan sehat kurang direspon oleh tukang sampah. Hal ini disebabkan oleh lokasi yang tidak mendukung (jalan sempit, becek, bau, tidak ada sarana untuk pemaparan materi seperti pengeras suara dan liannya), tukang sampah merasa tidak memerlukan masukkan mengenai masalah produktifitas kerja, dan banyak yang masih bekerja pada saat acara pengabdian masyarakat ini. Tetapi paling tidak bantuan yang diberikan dapat mengingatkan mereka akan pentingnya berperilaku bersih, menjaga kesehatan agar mereka dapat tetap bekerja mengumpulkan sampah atau produktif di bidangnya.

\section{DAFTAR PUSTAKA}

[1] Kamus Besar Bahasa Indonesia. Jakarta : Balai Pustaka, 2004

[2] Undang-Undang Republik Indonesia no 18 tahun 2018 tentang Pengelolaan Sampah

[3] Undang-undang Republik Indonesia no 36 tahun 2009 tentang Kesehatan

[4] Direktorat P2PTM Dirjen Pencegahan dan Pengendalian Penyakit Departeman Kesehatan, “Apakah Sehat dan Bugar?”, 2019

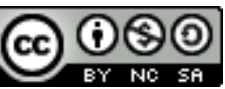

This work is licensed under a Creative Commons Attribution-NonCommercial-ShareAlike 4.0 International License. 